\title{
"Differences in Mental Attitude towards Extensive Dental Treatments between Two Siblings Suffering from Amelogenesis Imperfecta”-Two Case Reports and Literature Review
}

\author{
Khurshid Mattoo ${ }^{1, *}$, Nupur Rathi ${ }^{2}$, Roma Goswami ${ }^{3}$ \\ ${ }^{1}$ Prosthodontics, College of dental sciences, Gizan, KSA \\ ${ }^{2}$ Prosthodontics, Teerthankar dental college, Uttar Pradesh, India \\ ${ }^{3}$ Prosthodontics, Subharti dental college, Meerut, India \\ *Corresponding author: drkamattoo@rediffmail.com
}

Received September 28, 2014; Revised October 20, 2014; Accepted October 23, 2014

\begin{abstract}
Clinical conditions like amelogenesis imperfecta require extensive prosthetic rehabilitation that is strenuous to the clinicians and arduous for the patient. But when the results of such extensive treatment are fair to good, then satisfaction is also assured. Most of these cases require full mouth rehabilitation in the form of fixed Prosthodontics ranging from single crowns to fixed partial dentures. Patient mental attitude with will and determination play important role in the final outcome of such massive rehabilitation. This article discusses cases of siblings suffering from the same clinical condition yet having different will and determination. The article also presents ideal qualities that a patient should possess for any extensive medical or dental treatment and the reasons what actually motivates patients to undergo treatment.
\end{abstract}

Keywords: full mouth rehabilitation, multidisciplinary approach, root canal treatment, gingivectomy

Cite This Article: Khurshid Mattoo, Nupur Rathi, and Roma Goswami, “'Differences in Mental Attitude towards Extensive Dental Treatments between Two Siblings Suffering from Amelogenesis Imperfecta' -Two Case Reports and Literature Review.” International Journal of Dental Sciences and Research, vol. 2, no. 6 (2014): 123-127. doi: 10.12691/ijdsr-2-6-1.

\section{Introduction}

During the last two decades, psychologists have discovered that brothers and sisters raised together are almost as different in their personalities as people who grow up in separate families. From studies of twins raised together and apart, behavioral geneticists have concluded that only about 5 percent of the variance in individual personality traits is attributable to the shared environment, which is growing up in the same family, whereas 35 percent are associated with the non-shared environment. About 40 percent of the overall variance is believed to be genetic, and the remaining 20 percent is attributable to errors of measurement [1].

It may sound surprising, but it is true that the longest relationship that humans will experience in their lives is the relation between brothers and sisters, since every human outlives parent and they begin earlier than those we establish with our friends. The dynamics of relationships between brothers and sisters are complex and diverse. Some scientists have made efforts to characterize sibling behavior and psychology and codify it into welldefined themes, but in general, these relationships remain understudied and, therefore, somewhat mysterious. It is understandable that one cannot expect two brothers to show the same attitude towards treatment even if the underlying condition is severely handicapping the individuals. But what motivates one individual suffering from an inherited condition like amelogenesis imperfecta, and achieve his treatment objectives from his other sibling is a subject of research. A debilitating condition like amelogenesis imperfecta (AI) has been described as a complex group of inherited conditions that disturbs the developing enamel structure and exists independent of any related systemic disorder. [2-7] It is a rare enamel mineralization defect $[8,9]$ described by Spokes $[10,11]$ in 1890 as "hereditary brown teeth." It is recognized that more than 70 medical conditions present with intrinsic defects of enamel, but the term "amelogenesis imperfecta" should be limited to inherited disturbances of enamel formation not connected with local or systemic disorder. [12] Amelogenesis imperfecta manifests basically in three forms enamel hypoplasia, enamel hypocalcification, and enamel hypomaturation though these three forms of enamel defect may be caused by local or systemic factors [13].

Enamel hypo calcification is a defect in the mineralization process. In this form, enamel is soft and friable. [14] Hypomaturation is an abnormal occurrence in the final stages of the mineralization process. Hypomaturation 
differs from hypo calcification in that the enamel is harder with a mottled opaque white to yellow-brown or redbrown color. $[6,15,16]$ The most common form of AI is the autosomal dominant hypocalcified type, followed by hypomaturation, and the hypoplastic type. [17] AI is caused by mutations in a variety of genes that are critical for the normal enamel formation. A total of about five genes [AMELX, ENAM, KLK4, MMP20, and DLX3] $[18,19]$ have been associated with the condition. An amelogenin gene, located on the short arm of the $\mathrm{X}$ chromosome (Xp22.1-p22.3) has been identified for Xlinked AI in some families, confirming the existence of extensive allelic heterogeneity in this condition, [20,21,22,23] whereas autosomal dominant amelogenesis imperfecta has been localized to chromosome 4q [24].

Within affected families, there is an extremely variable clinical appearance of enamel hypoplasia, hypocalcification, or hypomaturation, depending on which stages of enamel formation are involved. [25] In general, both the deciduous and permanent dentitions are diffusely involved. [2,3,4,26,27].

Rehabilitation of patients with this clinical condition has always been a scientific, clinical, technical and a procedural challenge for many dental specialists. Besides these characteristics the dentist also needs to impose education, motivation, assurance and assertion to his patients. This clinical case report is about two brothers who had the same condition with varying severity but the attitude of both towards getting their respective treatment was quite different.

\section{Case Reports}

Two male patients related as brothers to each other, the elder one aged 32 years and the younger one aged 30 years were referred to the department of Prosthodontics from the department of oral medicine and radiology with a provisional diagnosis of amelogenesis imperfecta, for the rehabilitation of occlusion. Family history of both brothers revealed that their mother and sister were having similar dental problems with variable severity, different clinical picture and different mental attitude. Both the patients were from a low socioeconomic background and both were working in a shop owned by their father. Both were married, the elder one had two children, whereas the younger one had one child. Both the patients were living with their parents.

\subsection{Case 1}

Case 1 was diagnosed as $1 \mathrm{D}$ amelogenesis imperfecta as per Witkops classification. [12] A thorough dental, medical and social history was recorded. Clinical features included generalized discoloration with extrinsic staining, occlusal wear, sensitivity, and spacing with generalized gingivitis and localized periodontitis in relation to mandibular first molars on both sides (Figure 1). Radiographic examination revealed three impacted third molars out of which one of the coronal portion of the third molar had failed to develop. A periapical lesion in relation to mandibular left second molar was present (Figure 2). Clinical data required to plan rehabilitation included determination of interocclusal distance, existing vertical dimension of occlusion, closest speaking space, and the coincidence of centric occlusion with centric relation, oral hygiene index and tolerance of stomatognathic system to increase in the vertical dimensions of occlusion.

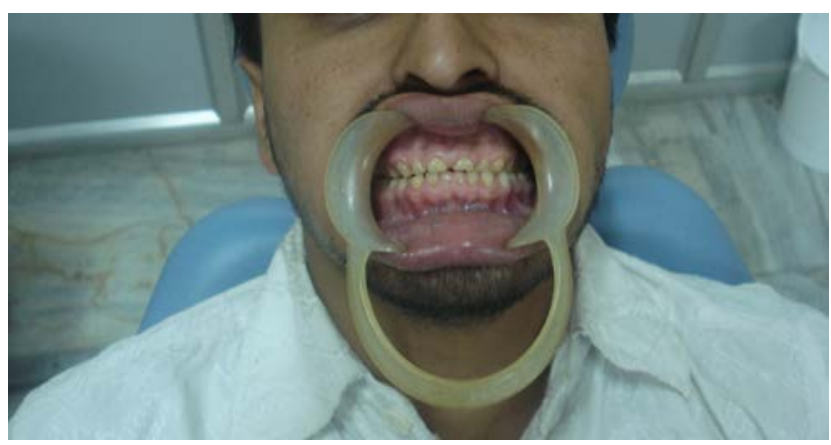

Figure 1. Intra oral view (Case 1) showing severe occlusal and labial wear

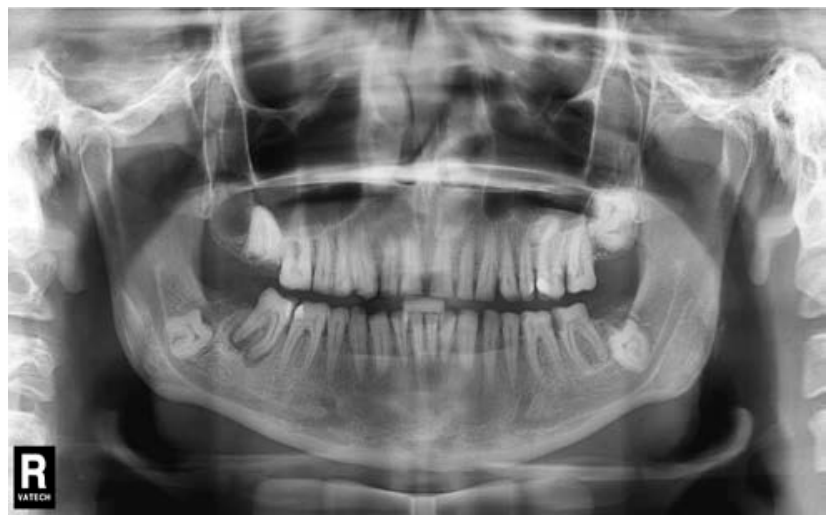

Figure 2. OPG (Case 1) showing classical dental features including nonformation of crown in relation to third molars

For effective, systematic and sequential treatment plan, diagnostic casts were mounted on Hanau Widevue semi adjustable articulator (Waterpik, Ft Collins, CO, USA) using an arbitrary face bow (Hanau Spring bow) and through centric and protrusive interocclusal records (Take 1, Kerr, Romulus, MI, USA). After thorough analysis a treatment plan of full mouth rehabilitation included pre mouth preparation in the sequential stage of extraction of impacted teeth, oral prophylaxis and hygiene maintenance, surgical crown lengthening of both arches and endodontic treatment of occlusally worn teeth (Figure 3).

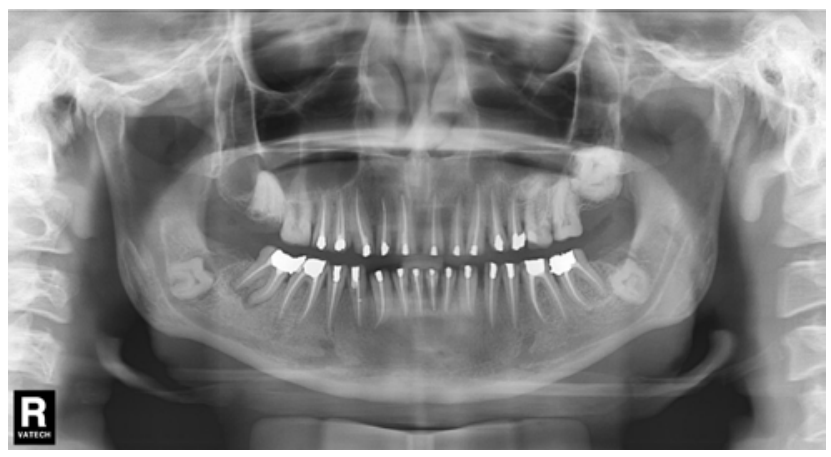

Figure 3. OPG (Case 1) showing extensive endodontic treatment of remaining natural teeth

The first step before starting the pre prosthetic mouth preparation was verifying the adverse effects, if any, towards an increase in occlusal vertical dimensions. This was done by making the patient wear a full occlusal splint for a period of 4 months. The patient was comfortable 
wearing the occlusal splint which was made at increased vertical dimensions of $2 \mathrm{~mm}$. After a period of about eight months during which, all necessary pre prosthetic mouth preparations were done, the rehabilitation of entire permanent dentition was started. Meanwhile mock preparations and pattern build up was carried on mounted diagnostic casts. Anterior guidance in the form of protrusive and lateral guidance's was established which would disclude the posterior teeth, so that a mutually protected occlusion could be incorporated in the final restorations.

The restorative treatment was started with mandibular anterior teeth and maxillary anterior teeth prepared at the same time. Final impressions were made in Vinyl polysiloxane impression material (Extrude and Extrude Extra; Kerr Corp) and master casts were prepared in type IV dental stone (Ultrarock, Kalabhai Dental, India). The master casts were mounted on the semi adjustable articulator and the articulator was programmed to the same values as during mock preparation and wax pattern fabrication. The anterior guidance was set so as to disclude the posterior teeth in protrusion. After wax pattern fabrication, the crowns were cast and finally finished and polished. Metal try in was done for all crowns and various shades were selected. The anteriors were cemented after porcelain trial and glazing with zinc phosphate cement (Harvard). The rehabilitation of posteriors was done first on the right side followed by the left side of the dental arch (Figure 4 and Figure 5).

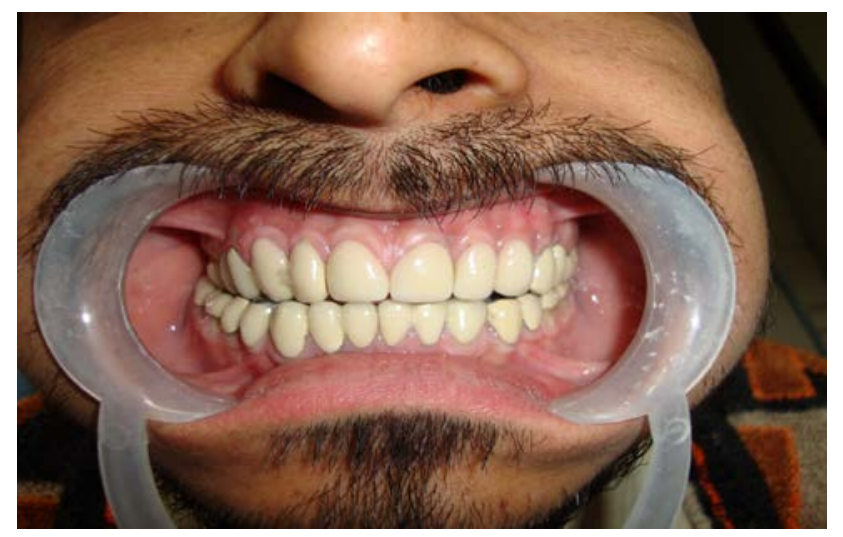

Figure 4. Maxillary and Mandibular rehabilitation (Case 1)

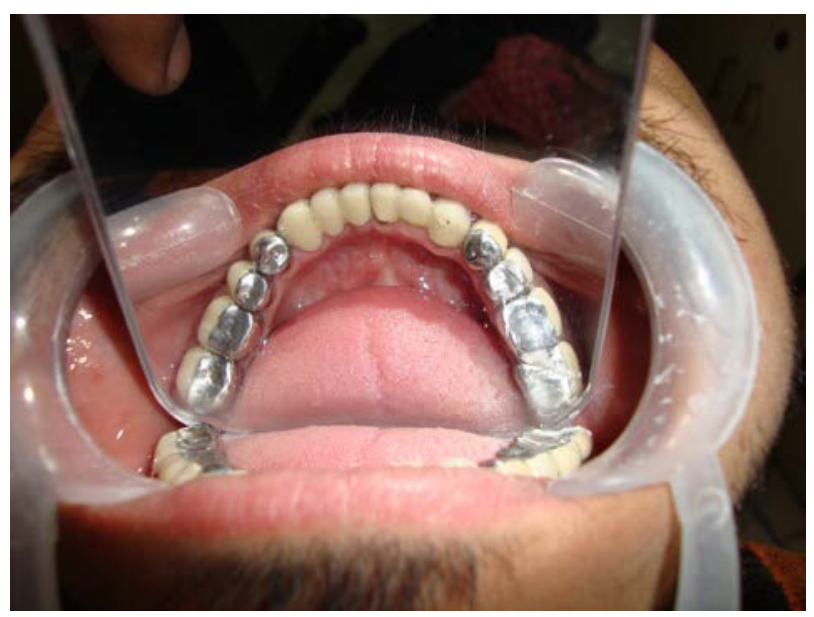

Figure 5. Occlusal view of the cemented restorations (Case 1)

\subsection{Case 2}

Case 2 was diagnosed with the similar condition. The patient was poorly built with wheatish complexion. Unique feature of his personality was his extreme shyness as compared to his brother. The patient's mandibular partially dentulous arch condition was more severe than his brother and included unerupted maxillary and mandibular second and third molars, multiple impacted mandibular anteriors and posteriors with retained mandibular deciduous teeth. The maxillary teeth were less affected and could have been easily restored (Figure 6 and Figure 7). After doing the necessary diagnostic wax up the patient was presented with the treatment option of fixed partial dentures and single crown for the maxillary arches in relation to anteriors and mandibular overdenture.

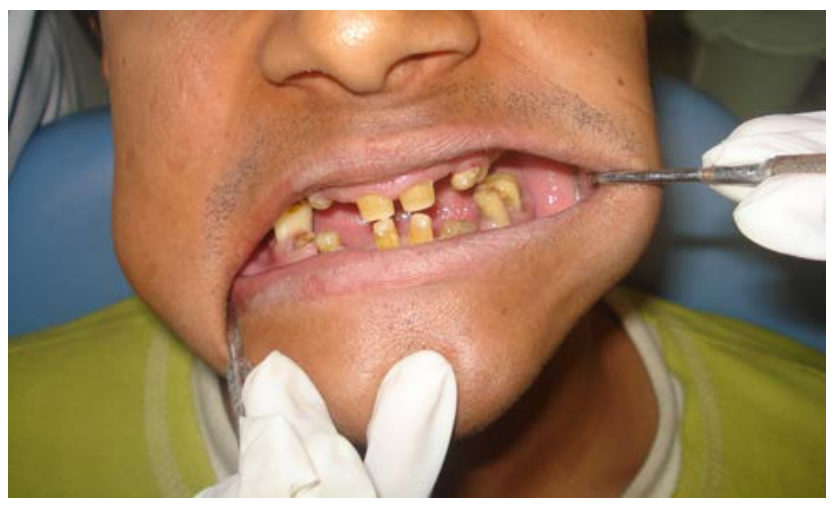

Figure 6. Intra oral view (Case 2) showing condition more severe than his brother

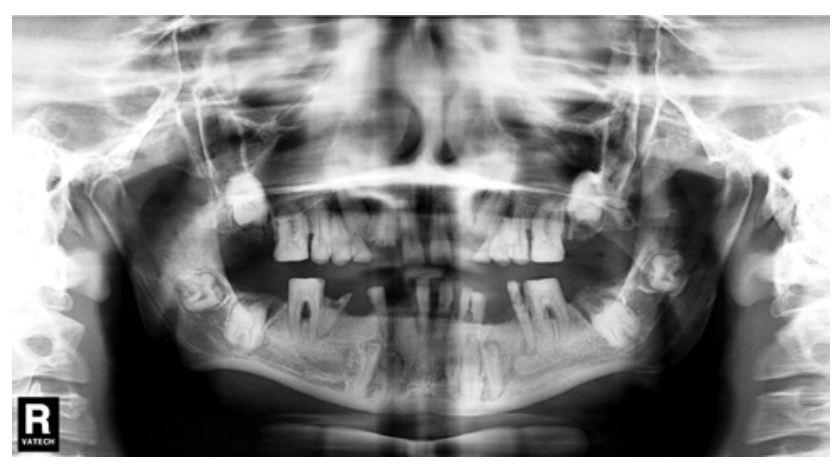

Figure 7. OPG (Case 2)

The treatment plan included oral hygiene maintenance program, extraction of certain retained teeth, endodontic treatment of supra erupted teeth and periodontal treatment of mandibular molars. The patient was informed about the number of visits and time that would be required to complete the treatment. The patient agreed to the treatment and came for the few visits during which diagnostic data was collected, but failed to report for treatment.

\section{Discussion}

The difference in mental attitude between siblings can be understood to a little degree based on modern health theory. The concepts of need and demand are central to this theory. The need can be defined as "the quantity of dental health care which expert opinion judges ought to be consumed over a relevant time period, in order to remain or become as dentally healthy as is permitted by existing knowledge.” [28] However, such a definition does not 
give attention to the individual's personal comfort and quality of life. Furthermore, it requires knowledge about the individual dental health situation, available treatment options and exact definitions of what should be regarded as dentally healthy $[29,30]$.

The decisive argument against such a definition is that it gives the power to decide need to someone other than the person who has the need. Thus, it contradicts the whole idea of patient empowerment, [31] which is the central tenet of the modern health theory. Need however defined does not always lead to demand for treatment, [31] depending on factors such as individual preferences, cost, cultural differences, psychosocial considerations, comfort, age and accessibility of services. Need and demand for Prosthodontic services are difficult to measure, as Prosthodontic treatment is highly individual and not directly related to, e.g., edentulousness $[32,33]$ or masticatory function. [33,34] In most industrialized countries the demand for Prosthodontic treatment is influenced by esthetic demands rather than a few missing teeth in the posterior regions [35].

From the above mentioned case reports, the need for rehabilitation evidently was more in case no 2 , who never turned for treatment. Between two brothers the esthetic and masticatory need was more for the case no 2. While interacting with him, he was appropriately educated about the effects of inappropriate mastication and its effect on general health. Every effort was made during his educational counseling about the advantages of full mouth rehabilitation. Financial consideration was also taken into account and both the siblings had no reservations regarding finance as such.

Many academicians will agree to the fact that completing the treatment in an academic institute requires appropriate time and number of appointments than what is done in a private set up. Reasons like minimum number of patients required to be treated on a daily basis, academic duties of staff and students, depending on other departments to complete treatment and more importantly time spent to teach students. But at the same time these very reasons make a patient extremely special because he shows determination, patience and will to complete his treatment. An example of such unsung hero is the case (case no 1) presented in this article that got his treatment completed during a period that extended more than a year. Both patients being poor were offered free treatment. But only one sibling went ahead showing his true grit to get rehabilitated. Over the period of one year the patient had more than forty appointments during which he was always regular and followed instructions with a lot of conviction. The other features of his mental attitude towards his rehabilitation included being on time for most of his appointments, regularity, following instructions given to him, having faith in his doctors ability and his decision making for him, enquiring more about things which he felt were difficult to understand, showing understanding if his doctor would be busy at times, calling the doctor in case he would counter any problem before making a visit to the hospital on his own, adjusting his personal schedule at his work according to his treatment visits, being less demanding including his appointment schedule, understanding the limitations of his prosthetic rehabilitation, following up regularly now for more than three years. On the other hand, his own sibling whose treatment was not as long as his brother's, showed reluctance to procedures involved during his diagnosis, absconded once his treatment plan was decided and never turned up.

One feature that could explain the reason for his reluctance to undergo further treatment was his extreme shyness. Studies that relate shyness of patients to his treatment needs are non-existent in the literature.

\section{Conclusion}

Full mouth rehabilitation of patients with severely compromised dentition is an area where research has been minimal. Most of the research is limited to case reports where technical things are mostly discussed. The real challenges are studies to understand the needs and demand for Prosthodontic treatment as there are very few such reports in the literature. [36] Various traits of a human being like shyness of the individual need to be explored in details so that it is possible to understand the need and demand of such patients. Only then our educational and motivational strategies will be successful which at present are not good enough to motivate such patients.

\section{Acknowledgement}

The authors would like to acknowledge Mr Sanawar Shuja and Mr Shahzad for their untiring help during the laboratory procedures of the treatment. The authors would also like to acknowledge all those patients who are determined to get their treatment done at the institute.

\section{References}

[1] Loehlin, John C. 1992. Genes and Environment in Personality Development. Newbury Park, CA: Sage Publications.

[2] Weinmann JP, Svoboda JF, Woods RW. Hereditary disturbances of enamel formation and calcification. J Am Dent Assoc 1945; 32: 397-418.

[3] Aldred MJ, Savarirayan R, Crawford PJM. Amelogenesis imperfecta: a classification and catalogue for the 21st century. Oral Diseases 2003; 9: 19-23.

[4] Neville BW, Damm DD, Allen CM, Bouquot JE. Oral and maxillofacial pathology. 2nd Ed. Philadelphia: Elsevier; 2002. p. 89-94.

[5] Robinson FG, Haubenreich JE. Oral rehabilitation of a young adult with hypoplastic amelogenesis imperfecta: a clinical report. J Prosthet Dent 2006; 95 (1): 10-3.

[6] Sari T, Usumez A. Restoring function and esthetics in a patient with amelogenesis imperfecta: a clinical report. J Prosthet Dent 2003; 90 (6): 522-5.

[7] Lykogeorgos T, Duncan K, Crawford PJ, Aldred MJ. Unusual manifestations in X-linked amelogenesis imperfecta. Int J Paediatr Dent 2003; 13: 356-361.

[8] Soares CJ, Fonseca RB, Martins LR, Giannini M. Esthetic rehabilitation of anterior teeth affected by enamel hypoplasia: a case report. J Esthet Restor Dent 2001; 14: 340-8.

[9] Crabb JJ. The restoration of hypoplastic anterior teeth using an acid-etched technique. J Dent 1975; 3: 121-4.

[10] Lindunger A, Smedberg JI. A retrospective study of the prosthodontic management of patients with amelogenesis imperfecta. Int J Prosthodon, 2005; 18 (3): 189-94.

[11] Spokes C. Case of faulty enamel. Br J Dent Sci 1890; 33: 750-752.

[12] Witkop Jr CJ: Amelogenesis imperfecta, dentinogenesis imperfecta and dentin dysplasia revisited Problems in classification. J Oral Pathol 1988: 17; 547-53.

[13] Bhussry BR. Development and growth of teeth. In Bhaskar SN (Ed): Orban's Oral Histology and Embryology (Ed 8). St. Louis, MO, Mosby, 1976, pp 23-104. 
[14] Bouvier D, Duprez JP, Pirel C, Vincent B. Amelogenesis imperfecta-a prosthetic rehabilitation: a clinical report. J Prosthet Dent 1999; 82: 130-1.

[15] Witkop CJ Jr, Kuhlmann W, Sauk J. Autosomal recessive pigmented hypomaturation amelogenesis imperfecta. Report of kindred. Oral Surg Oral Med Oral Pathol 1973; 36: 367-82.

[16] Ooya K, Nalbandian J, Noikura T. Autosomal recessive rough hypoplastic amelogenesis imperfecta. A case report with clinical, light microscopic, radiographic, and electron microscopic observations. Oral Surg Oral Med Oral Pathol 1988; 65: 449-58.

[17] Kostoulas I, Kourtis S, Andritsakis D, Doukoudakis A. Functional and esthetic rehabilitation in amelogenesis imperfecta with allceramic restorations: a case report. Quintessence Int 2005; 36 (5): 329-38.

[18] Wright JT. The molecular etiologies and associated Phenotypes. Am J Med Genet A, 2006; 140(23): 2547-55.

[19] Stephanopoulos G, Garefalaki ME, Lyroudia K. Genes and related proteins involved in amelogenesis imperfecta. J Dent Res 2005; 84 (12): 1117-26.

[20] Mardh CK, Backman B, Simmons D, et al. Human ameloblastin gene: genomic organization and mutation analysis in amelogenesis imperfecta patients. European Journal of Oral Science 2001; 109: 8-13.

[21] Collier PM, Sauk J, Rosenbloom SJ et al. An amelogenin gene defect associated with human X-linked amelogenesis imperfecta. Archives of Oral Biology 1997; 42: 235-42.

[22] Lench NJ, Winter GB: Characterization of molecular defects in Xlinked amelogenesis imperfecta (AIII1). IIum Mutat 1993; 5: 25 1259.

[23] Crawford PJ, Aldred MJ: Clinical features of a family with Xlinked amelogenesis imperfecta mapping to a new locus (AM3) on the long arm of the X chromosome. Oral Surg Oral Med Oral Pathol 1993; 76: 187-191.

[24] Forsman K, Lind L, Backman B, et a1. Localization of a gene for autosomal dominant amelogenesis imperfecta (NAI) to chromosome 4q. Hnm. Mol Genet 1993: 3621-1625.
[25] Aldred MJ, Crawford PJM. Molecular biology of hereditary enamel defects. Ciba Found Symp1997; 205:200-209.

[26] Neville BW, Damm DD, Allen CM, Bouquot JE. Oral and Maxillofacial Pathology. Philadelphia: WB Saunders Company. 1995; p. 79-84.

[27] Collins MA, Mauriello SM, Tyndall DA, Wright JT. Dental anomalies associated with amelogenesis imperfecta: a radiographic assessment. Oral Surg Oral Med Oral Pathol Oral Radiol Endod 1999; 88: 358-364.

[28] Spencer AJ. The estimation of need for dental care. J Public Health Dent. 1980: 40: 311-327.

[29] Jeffers JR, Bognanno MF, Bartlett JC. On the demand versus need for medical services and the concept of "shortage." Am J Public Health 1971; 61: 46-63.

[30] Beazoglou T, Brown LJ, Heffley D. Dental care utilization over time. Soc Sci Med 1993; 37: 1461-1472.

[31] US Department Of Health And Human Services. Oral Health in America: A Report of the Surgeon General. Rockville, MD: National Institute of Dental And Craniofacial Research, 2000.

[32] Basker R, Mullane DM, Removable Prosthodontic Services Related To Need And Demand. In: Owall B, Kayser AF, Carlsson GE (Eds). Prosthodontics. Principles and management strategies. London: Mosby - Wolfe, 1996: 223-235.

[33] Todd JE, Lader D, Adult Dental Health. 1988; London: Her Majesty's Stationery Office. 1991

[34] Kayser AF Witter DJ, Oral function needs and its consequences for dentulous older people. Community Dent Health 1985; 2: 285291.

[35] Oosterhaven SP, Westert GP, Schaub RMH. Perception and significance of dental appearance, the case of missing teeth. Community Dent Oral Epidemiol 1989; 17: 123-126.

[36] Eklund SA, Burt BA. Risk factors for total tooth loss in the United States, longitudinal analysis of national data. J Public Health Data 1994; 54: 5-14. 